\title{
Case-based Perspective-Taking as a Mechanism to Improve Metacognition and Higher-Level Thinking in Undergraduate Speech-Language Pathology Students
}

\author{
Lisa Vinney \\ Illinois State University \\ lavinne@ilstu.edu \\ Jennifer C. Friberg \\ Illinois State University \\ jfribe@ilstu.edu \\ Mary Smyers \\ Illinois State University \\ mmsmyer@ilstu.edu
}

Abstract. This case study addressed the authors' efforts to design an 8-week small-group independent study (IS) experience that facilitated undergraduate speech-language pathology students' ( $n=19$ ) higher-level thinking and overall metacognitive awareness. We hoped to encourage both in order to improve students' overall cognitive growth while enhancing their reflection about and knowledge of professional perspectives regarding the assessment and treatment of laryngeal cancer. To take on this challenge, we combined case-based learning (CBL) and perspective-taking (PT) pedagogies across the IS. Students completed the Metacognitive Awareness Inventory (MAI) pre- and post-IS, and written reflections after each of eight weekly discussion meetings. The $M A I$ was quantitatively analyzed, while reflections were qualitatively coded using Bloom's taxonomy. Findings indicated that metacognitive awareness significantly improved and that higher-level cognitive processing was increasingly evidenced across students' IS experience. Results indicate the potential to maximize metacognition and cognitive processing by combining CBL and PT by the methods used here. Applications of combined CBL and PT to other disciplines and teaching and learning situations will be discussed along with the implications of our findings.

Keywords: Metacognitive awareness, case-based learning, perspective-taking, cognitive processing

Since the first work on active learning in 1991 (Bonwell \& Eison), teaching pedagogies that involve learning through doing tasks versus receiving information have been firmly espoused by educational researchers and practitioners (Fink, 2013; Barkley, 2010). In particular, active learning represents a cultural shift away from the traditional lecture. Instead, classroom instruction is designed to facilitate experiential learning, followed-up by reflection on what was learned and how one is learning alone and with others (Fink, 2013). By setting up the classroom in this way, it is thought that higher-level learning and metacognitive awareness may be fostered (Richmond \& Hagan, 2011; Vos and De Graaff, 2004).

Why metacognition?

Metacognition was first introduced by Flavell (1979) to describe self-cognitions, or thoughts about one's own thinking. It includes the subcategories of knowledge (knowledge about thinking in general 
and one's own thinking) and regulation of that knowledge via cognitive strategies, etc. (controlling learning via activities that foster monitoring and controlling cognitions; Dunlosky \& Metcalfe, 2009; Schraw, 1998). For example, metacognitive knowledge is linked to the following (Schraw, 1998; Schraw \& Dennison, 1994):

- Declarative knowledge (knowledge of one's own cognitive skills or what one knows or needs to acquire to think through a topic)

- Procedural knowledge (understanding how one learns)

- Conditional knowledge (comprehension of different learning strategies and the ability to justify why one might use a strategy in a specific context)

On the other hand, metacognitive regulation involves:

- Planning (setting learning goals)

- Information management strategies (managing and processing information by classifying it or condensing broad concepts into succinct descriptions)

- Monitoring (evaluating the effectiveness of learning strategies used)

- Debugging strategies (using strategies to improve comprehension or correct misunderstandings or task errors)

- Evaluation (analyzing the success of learning strategies used, or the effectiveness with which one performs a task following the use of such strategies)

Thus, metacognitive regulation is often engaged in to attain some learning or behavioral goal. Goal attainment further calls upon self-regulatory processes related to attentional resources, impulse and emotional control, action maintenance, planning, and task performance (Vohs \& Baumeister, 2004). Metacognition allows learners to critically evaluate and shape their future learning and behavior. Further, it is tied to strong learning gains and greater success on a range of cognitive tasks, better use and focus of attentional resources, and more precise self-evaluations of learning (Dunlosky \& Metcalfe, 2009; Koriat, Ackerman, Locke, \& Schneider, 2009; Prins, Veenman, \& Elshout, 2006; Nelson \& Dunlosky, 1991; Koriat \& Bjork, 2006; Koriat, 2008; Schraw, 1998).

Metacognitive awareness describes having a clear understanding of ones own thinking such that metacognitive knowledge and regulation are supported and strengthened. Young \& Fry (2008) found that junior and senior education undergraduate students who scored higher on a self-report measure evaluating metacognitive awareness and its subdomains of metacognitive knowledge and regulation (the Metacognitive Awareness Inventory (MAI); Schraw and Dennison, 1994), had better overall grade point averages (GPAs) than those who scored significantly lower on the MAI. Graduate education students scored significantly higher on the metacognitive regulation sub-section of the MAI, but demonstrated statistically similar performance on measures of metacognitive knowledge as undergraduate students. These findings indicate that more experienced students may have stronger strategies for regulating their cognitions (i.e. assessing test performance accuracy), and that metacognitive regulation (as opposed to metacognitive awareness) may be most facilitative of gains in learning and academic performance (Schraw, 1994). Similarly, Rum and Ismail (2014) found a strong correlation between the MAI and GPA of students enrolled in introductory computer programming coursework regardless of academic standing.

Greater metacognition and self-regulation are highly correlated with self-efficacy (BartimoteAufflick, Bridgeman, Walker, Sharma, and Smith, 2016) or the belief that one can take on a specific task (Bandura, 1977). In turn, self-efficacy exhibits a strong relationship with student learning 
outcomes, further suggesting that improved metacognition and self-regulation may mediate increases in self-efficacy and vice-versa.

Schraw (1998) suggests that metacognition may be promoted by group discussion and activities which allow students to share and reflect upon their self-cognitions in relationship to specific content. This practice should effectively facilitate metacognitive skills and promote metacognitive awareness. After all, reflection requires the monitoring and evaluating of one's own thought processes for accuracy. Thus, engaging in reflection facilitates practice of metacognitive regulation. Further, by listening to how others evaluate their own thought processes, individuals with poorer metacognitive regulation may learn new and different strategies to control and monitor their own cognitions.

\section{Higher levels of cognitive processing and metacognition}

Bloom's taxonomy offers a specific way to differentiate higher levels of cognitive processing from lower ones (Bloom, Englehart, Furst, Hill, \& Krathwohl, 1956; Adams, 2015; noted below with an evolving example of the cognitive skills used at each level):

- Knowledge (labeling different parts of the brain on a 2-dimensional blank picture)

- Understanding (matching functional properties with each brain region)

- Application (predicting resulting symptoms from damage to a specific brain region)

- Analysis (interpreting case information to determine which brain regions are potentially injured based on cognitive, behavioral, and emotional patterns)

- Synthesis (identifying tasks that may determine the integrity of different brain regions)

- Evaluation (providing a rationale for or against the tasks noted above under Synthesis.)

Past research indicates that metacognitive knowledge and regulation improves when higherlevel cognitive skills are used during learning. Reciprocally, more sophisticated metacognition is often noted when individuals are using higher-level cognitive skills; both of which ultimately result in improved learning (Chin \& Brown, 2000; Magno, 2010). Higher-level cognitive processing is associated with what is known as a deep approach to learning, or a focus on understanding new material. By exploring relationships between concepts, prior knowledge, and personal experiences, as well as retrieving new information and applying it to situations, deep learning is expected to be facilitated (Biggs, 2003). A surface approach to learning is focused on knowledge (i.e. rote recall of information), the lowest level of Bloom's taxonomy. This approach does not emphasize deep understanding and making connections between other concepts, tasks, or experiences (Biggs, 1987; Chin \& Brown, 2000). Given that deep approaches to learning (i.e. application, analysis, synthesis, etc.) are focused on meaning-making versus rote memorization of knowledge or facts, it is not surprising the metacognitive regulation (i.e. planning, information management, monitoring, debugging, etc.) would be necessary to support higher-level cognitive processes.

\section{Promoting metacognitive awareness and higher-levels of cognition}

While active learning includes any situation that facilitates engagement in experiences and reflection on those experiences, specific types of active learning pedagogies may be uniquely suited to promote metacognition and higher-level cognitive processing.

Case-based learning (CBL). CBL is an active learning instructional pedagogy that requires students to discuss and analyze real-life case scenarios from their discipline collaboratively and cooperatively. Students engaged in CBL are asked to describe their thinking process about case 
features to a group (i.e. metacognitive knowledge; Trommelen, Karpinski, \& Chauvin, 2017). Likewise, cases engage students in clinical reasoning which requires deep (higher-level) versus surface processing of information. Further, application of prior knowledge and understanding of a topic, and synthesizing, or evaluating cases to facilitate higher-level cognitive processing and metacognition are commonly targeted (Trommelen, Karpinski, \& Chauvin, 2017). The implementation of CBL is tied to significantly better test performance from pre- to posttest when compared to lecture alone (Datta \& Ray, 2016). Further, discussions surrounding cases may provide an opportunity for students to engage in cooperative learning, enhance emotional engagement with content to foster learning outcomes, and improve interactions between students in the classroom (Nkhoma, Sriratanaviriyakul \& Le Quang, 2017; Foran, 2002).

Perspective-taking. DeBono's "Six Thinking Hats" (1985) is a strategic pedagogy that facilitates metacognitive awareness via a framework describing six different thinking processes. This pedagogy can be applied to the examination of cases, questions, or problems. The original iteration of this pedagogy tasked students with wearing colored hats to explicitly represent each of the six thinking processes DeBono described including:

- Presenting evidence about a given course topic (What do we know about this topic?)

- Questioning assumptions and/or challenging peers to think differently about a topic to generate alternatives or new ways of thinking about a subject (What are some creative ideas regarding this topic?)

- Advocating for the use/implementation/acceptance of the alternative(s) (What evidence supports the use of these creative ideas?)

- Challenging the use/implementation/acceptance of the topic being discussed (What are some potential concerns or problems with these ideas?)

- Expressing emotion to share positive, negative, and/or neutral feelings about a topic (What are the feelings or opinions about these potential alternatives?)

- Regulating and reflecting upon the results of the thinking processes discussed above (What are some conclusions or decisions that can be made about this topic? What else should be considered? How else can we think about this topic?)

By putting on different thinking hats (applying various thinking strategies) in parallel as a topic is discussed, metacognitive knowledge and practice of metacognitive regulation may be reinforced. In regards to knowledge, by approaching a particular topic or scenario in this way, students may gain a greater awareness as to what thinking strategies work best in particular situations as well as their own cognitive processes and habits. On the other hand, metacognitive regulation is put into practice by the "six hats" methods when student implement cognitive strategies, and monitor and evaluate those strategies.

These approaches may be explicitly assigned as a process like the example above. However, role-playing that involves students taking on the perspective of different stakeholders for a situation or problem may potentially facilitate using the "six hats" strategy implicitly. For example, asking students to think as if they were a doctor, nurse, speech-language pathologist, spouse, dietitian, psychologist, etc. when approaching a complex clinical problem is likely to lead to similar cognitive processes, based on each stakeholder's unique point of view. As a result, students may integrate many different perspectives into how they might manage the scenario in question.

Such a strategy is likely to lead to students sharing their own thought processes which may further their own and other group members' metacognitive knowledge and regulation. Likewise, perspective-taking (PT) likely requires students to not only engage in metacognition, but also higher-

Journal of the Scholarship of Teaching and Learning, Vol. 19, No. 3, June 2019. josotl.indiana.edu 
level cognitive processing by using baseline knowledge and understanding to apply, analyze, synthesize, or evaluate the targeted problem or idea based on an assigned role. Finally, there is evidence that such a strategy may allow students to practice facilitating effective communication and empathy that may be especially important during students' future work (Vescio, Sechrist, \& Paolucci, 2003; Galinsky \& Ku, 2004). Facilitating empathy via PT has been known to have real world consequences such as greater patient satisfaction (Blatt, Lelacheur, Galinsky, Simmens, \& Greenberg, 2010).

\section{Learning scenario}

One challenge of working with undergraduate students studying clinical professions involves facilitating their higher-level cognitive processing of disciplinary content and overall development as learners via improvements in metacognition. For example, we believed there was a crucial need to expose undergraduate Communication Sciences and Disorders students to the multidisciplinary assessment and management of laryngeal cancer while facilitating metacognitive development and higher-level (deep) learning and cognitive processing. Our approach to accomplishing these objectives was to combine CBL and PT into a case-based perspective-taking (CBPT) pedagogy during an 8-week small-group learning experience. As detailed above, it is likely that CBL and PT foster both metacognition and higher levels of cognitive processing separately. Thus, we hoped that implementation of CBPT would result in global improvements in metacognition and deeper processing of disciplinary content for students across an 8-week learning experience. We chose to examine the effectiveness of CBPT via the following research questions:

1. Will students' metacognitive awareness significantly increase from pre- to post- learning experience?

2. Did students' learning change across the experience such that a trend towards higher-level cognitive processing was reflected?

\section{Methods}

\section{Context of learning experience}

Nineteen students participated in 8-weeks of discussion-based activities as part of an independent study (IS) focused on the interdisciplinary management of laryngeal cancer. Seven students participated in the IS experience in the fall of 2016 while the remaining students completed their IS in the spring of 2017. IS content and procedures were identical across both semesters. All participants were female undergraduate speech-language pathology majors. The IS experience was facilitated by two faculty members (first and second author of this paper) and one graduate assistant who had previous exposure to various topics across the IS experience. The IS was not a required element of any student's plan of study; however, students did earn variable, elective credit (1-3 credits) for their efforts and participation.

While participating in the IS, students met with one or more facilitators for weekly one-hour discussion sessions. Students prepared for each IS session by completing pre-selected readings from an assigned text (Author \& Author, 2017). During IS meetings, facilitators introduced a series of CBPT activities related to the content of their assigned readings. These activities required that students discuss specific clinical cases by taking on the perspectives of various stakeholders important to the management of laryngeal cancer (e.g., patient, family, doctor, psychologist, employer). An example of one CBPT activity used as part of the IS experience can be found in Appendix A. 
Following each weekly meeting, students completed reflections on their learning, specifically in relationship to the topic of discussion for each week, as well as general insights about the management of laryngeal cancer. Five questions were provided to students to structure these weekly reflections:

1. After completing my readings and participating in IS activities, what important insights have I noted?

2. What questions do I have about this material after reading/participating in discussion?

3. Did I find this material interesting? Why/why not?

4. What information conflicted with my own experience/perspective?

5. How did our discussion/activity this week impact my learning?

Students submitted reflections electronically to the week's facilitator, who then provided responses to each student's reflection to answer questions, and acknowledge students' perceptions of their learning.

\section{Data collection \& analysis}

Data were harvested from a variety of sources to better understand the impact of CBPT on student learning and metacognition. Weekly student reflections served as one data source. Students also completed the MAI and all nine sub-sections constituting metacognitive knowledge (declarative, procedural, and conditional knowledge) and regulation (planning, information management strategies, monitoring, debugging strategies, evaluation; Schraw and Dennison, 1994) prior to the IS experience and following its completion.

Data were analyzed qualitatively and quantitatively to determine the impact of CBPT on student learning. MAI data were analyzed quantitatively to measure changes over time in terms of students' metacognitive awareness. Weekly reflection data for each participant were analyzed qualitatively, using a categorical approach to analysis to identify any changes in the levels of cognitive processing observed across the IS experience.

Quantitative analysis. Of the 19 participants involved in the IS, data for students' pre- and postIS experience, MAI was used for 18 of the 19 students, as one student only provided post-MAI data. Due to the small sample size, a Wilcoxon signed-rank test was used to determine whether significant differences were found from pre- to post-IS experience overall, in terms of metacognitive knowledge, metacognitive regulation, and the specific sub-components of these processes. Alpha level was set at .05 .

Qualitative analysis. A verbatim transcript from each participant's weekly reflections was used to measure levels of cognitive processing. To accomplish this task, reflection data were analyzed using Bloom's Taxonomy (Bloom, Englehart, Furst, Hill, \& Krathwohl, 1956). Analysis via Bloom's was meant to identify changes in the complexity and consciousness of thought, as both underly cognitive growth (Author, 2012; Maslovaty, Cohen, \& Furman, 2008). To understand changes in higher-level thinking across the IS experience, transcripts from week 1, week 4, and week 8 of the IS were reviewed by the third author of this study, who applied the six categories of Bloom's taxonomy (knowledge, comprehension, application, analysis, synthesis, evaluation) to reflection data. Authors agreed that as changes in higher-level thinking occur incrementally, analyzing the first, middle, and last weeks of student reflection data was appropriate. Across all transcripts, these categories were assigned to describe changes in the levels of cognitive processing observed across the IS experience.

Journal of the Scholarship of Teaching and Learning, Vol. 19, No. 3, June 2019.

josotl.indiana.edu 
Inter-rater agreement for the qualitative analysis of reflection data was measured as follows: A random sample of data points per transcript were also coded for level of cognitive processing by the first and second authors and compared to the initial analysis completed by the third author. Over $90 \%$ agreement was found across raters. In instances where differences in assigned codes/categories were identified, authors discussed each until consensus was reached.

Table 1: Pre- \& post-IS MAI data

\begin{tabular}{|l|l|l|}
\hline & Pre-IS mean (SD) & Post-IS mean (SD) \\
\hline Declarative Knowledge & $7.44(.71)$ & $7.67(.77)$ \\
\hline Procedural Knowledge & $3.67(.49)$ & $3.72(.46)$ \\
\hline Conditional Knowledge & $4.44(.62)$ & $4.67(.59)$ \\
\hline Overall Knowledge of Cognition & $15.56(1.19)$ & $16.06(1.21)$ \\
\hline Planning & $5.28(1.44)$ & $6.11 * *(1.10)$ \\
\hline Information Management Strategies & $8.67(1.03)$ & $9.0(.91)$ \\
\hline Comprehension Monitoring & $5.83(.86)$ & $6.11(1.18)$ \\
\hline Debugging Strategies & $4.89(.32)$ & $4.94(.24)$ \\
\hline Evaluation & $4.61(1.09)$ & $5.28(1.10)$ \\
\hline Overall Regulation of Cognition & $29.28(3.3)$ & $31.44 * *(3.3)$ \\
\hline Total MAI Score & $45.11(4.28)$ & $47.50 * *(4.25)$ \\
\hline
\end{tabular}

$* *(\mathrm{p}<.05)$

\section{Outcomes}

\section{MAI data}

A Wilcoxon signed-rank test determined that there were statistically significant increases in students' MAI scores for only the regulation of cognition section from pre-IS $(\mathrm{Mdn}=29.5)$ to post-IS $(\mathrm{Mdn}=32$, $\mathrm{z}=-2.28, \mathrm{p}=.022$ ), but not for the knowledge of cognition section (pre-IS, $\mathrm{Mdn}=16$ and post-IS $\mathrm{Mdn}=16, \mathrm{z}=-1.59, \mathrm{p}=.11)$. The planning sub-section of the MAI regulation of cognition section significantly increased from pre-IS ( $\mathrm{Mdn}=5.5)$ to post-IS ( $\mathrm{Mdn}=6, \mathrm{z}=-2.66, \mathrm{p}=.008)$, as did total MAI scores from pre $(\mathrm{Mdn}=46)$ to post $(\mathrm{Mdn}=49, \mathrm{z}=-2.18, \mathrm{p}=.029)$. No statistically significant findings were noted for the remaining eight sub-categories of regulation and knowledge of cognition. See Table 1 for pre- to post-IS mean scores by MAI category. 


\section{Levels of cognitive processing}

While the analysis described above allowed investigators to better understand the various forms of learning experienced by students across their IS experience, it did not yield information about changes in cognitive processing. Analysis of students' reflections using Bloom's taxonomy identified changes in the complexity of cognitive processing, with more reflection statements indicating low-level cognitive processing early in the IS experience. For example, one student indicated understanding "more about the different surgical and treatment approaches that can be taken when a patient is diagnosed with laryngeal cancer" following an early IS discussion. This statement demonstrated the cognitive processing level of knowledge. Another student demonstrated the cognitive processing level of comprehension when she noted that "every person on the care team plays a big role when it comes to supporting the patient."

A move towards higher-level processing of core material was noted towards the end of the IS experience. For example, application was demonstrated in the following: "I was able to connect this to a broader point of view that it is important for a patient to have support in his/her environment no matter where they turned," while another student's reflection was coded as analysis: "I feel if a patient has some aspect of his/her life that will remain constant, such as family, friends, or community, that he/she will be able to look at things with a slightly healthier outlook." One student noted the highest level of cognitive processing in this study (synthesis) when she indicated, "perspective-taking exercises increased my ability to consider so many angles and helps me practice thinking about others' opinions and thoughts, something that will be important as a future clinician to be able to counsel patients on their individual concerns."

\section{Table 2: Frequency table for levels of cognitive processing data}

\begin{tabular}{|l|l|l|l|}
\hline & Week 1 & Week 4 & Week 8 \\
\hline Knowledge & 227 & 152 & 113 \\
\hline Comprehension & 48 & 70 & 114 \\
\hline Application & 16 & 18 & 76 \\
\hline Analysis & 1 & 14 & 35 \\
\hline Synthesis & 0 & 2 & 15 \\
\hline Evaluation & 0 & 0 & 0 \\
\hline
\end{tabular}

While the greatest number of reflection statements demonstrated knowledge-level learning ( $\mathrm{n}=492$ ), 50\% fewer knowledge statements were observed in week 8 than in week 1, demonstrating an overall decrease in this lowest level of cognitive processing. The remaining levels of cognitive processing measured (comprehension, application, analysis, and synthesis) increased from week 1 to week 8, indicating that while the lowest level of learning (knowledge) decreased over time, higher levels of cognitive processing were consistently observed as the IS timeline progressed. No instances of the highest level of learning (evaluation) were noted at any point across weeks 1,4 , or 8 (see Table 2). 


\section{Discussion}

Overall, it appears that the use of CBPT may have facilitated gains in metacognitive awareness and increases in higher-level cognitive processing of core content knowledge. Specifically, reflective statements across two cohorts of students from week 1, to week 4, to week 8 of the IS increasingly exhibited changes in the sophistication of cognitive processing. Thus, a decrease in statements reflecting the knowledge cognitive domain was noted across the three weeks examined. On the other hand, statements reflecting the higher-level cognitive domains of comprehension, application, analysis, and synthesis were noted. Students' overall metacognitive awareness and regulation also improved from pre to post-IS, as did their self-perceived ability to engage in planning (i.e. goal setting) prior to learning experiences. Additionally, it is notable that changes were observed over a relatively short amount of time, indicating that focused strategies, such as CBPT, can potentially lead to improvements in higher-level cognitive processing and metacognitive awareness within a single academic term.

\section{Improvements in regulation of cognition}

While metacognitive awareness improved overall, only a significant improvement in the broad category of metacognitive regulation was discovered from pre- to post-IS, as metacognitive knowledge did not significantly change during this timeframe. Given that metacognitive regulation may be more integral to learning, academic performance, and success in advanced study (Young \& Fry, 2008; Schraw, 1994), this finding is especially notable. Additionally, the planning sub-category within the broad category of regulation of cognition significantly improved from pre- to post-IS. No sub-domain significantly improved from to pre- to post-IS for the broad category of metacognitive knowledge.

Planning items on the MAI focus on determining the most important learning objectives, setting specific goals, reading instructions with care, asking questions prior to task initiation, thinking of multiple ways to solve a problem, and managing time effectively. CBPT may be especially likely to foster the planning sub-domain due to its focus on problem-solving from a multitude of perspectives. Further, students were tasked with setting goals for preparedness and reading with care as they were exposed to this systematic pedagogical framework repeatedly. In turn, during weekly meetings, students engaged in CBPT activities, facilitating practice in problem-solving from a variety of viewpoints and choosing solutions for problems to mesh with their assigned role(s). Finally, postmeeting reflections allowed students to synthesize their learning, integrating new information with previous knowledge as a foundation for future IS topics.

\section{Higher levels of cognitive processing}

Knowledge and comprehension continued to be the most predominant codes assigned over the course of the IS. Likely, students were exposed to new content weekly that required cognitive processing and storage. However, trends indicate that while knowledge was the most frequently observed level of cognitive processing, the frequency with which this code was observed decreased by $50 \%$ from week 1 to week 8. During this same time frame, comprehension codes more than doubled. It could be that as time went on, student became more familiar with terms and information related to LC. As a result, demonstration of knowledge through basic retrieval of terms and facts became less pertinent whereas demonstrating advanced comprehension (i.e. comparing and contrasting, summarizing ideas, etc.) was facilitated by the CBPT model. In particular, students increasingly were tasked with comparing and contrasting clinical approaches to LC management specific to their assigned perspective, while summarizing ideas and concepts in their weekly reflections.

Journal of the Scholarship of Teaching and Learning, Vol. 19, No. 3, June 2019. josotl.indiana.edu 
Application codes quadrupled from week 1 to week 8, which was expected, as students applied knowledge to solve problems in different ways as part of the CBPT framework. What was more surprising given students' limited prior exposure to LC, was that increases in analysis and synthesis were noted across the IS experience. Analysis involves seeing relationships amongst ideas. Given that CBPT requires students to take apart specific aspects of LC, particularly in case study format, students likely practiced analysis each week of the IS experience. Synthesis codes may have emerged from practice adapting, elaborating, and theorizing approaches to case-based questions. Despite practice with several higher levels of cognitive processing, it is unlikely that students in the IS had enough depth and breadth of professional knowledge after 8 weeks of CBPT to engage in behaviors connected with evaluation, which is why this code was not observed.

\section{Applying CBPT beyond CSD}

While CBPT was developed for use with speech-language pathology students, any situation in which a case-based approach can be merged with the need to understand the perspective of different stakeholders in a given context would be appropriate for the application of CBPT as an instructional approach (Author \& Author, in submission). For instance:

- An instructor for a business-related course might use CBPT to simulate a hiring/firing situation. Students could take on the roles of employee, supervisor, human resources manager, or other personnel to explore the ins and outs of the employment process.

- In a physics course, an instructor may assign different "perspectives" to properties such as force, mass, or gravity. Students could, in turn, determine how these variables interact to promote a physical phenomenon.

- In a course focused on special education planning, CBPT could be used to better understand an interdisciplinary approach to working with a child with autism. Students could adopt the perspective of teachers, parents, students, teacher aides, therapists, administrators, etc., when writing goals and objectives for educational planning.

- A variety of clinical fields outside of CSD could use CBPT, as well. Instructors for dietetics, nursing, rehabilitative therapies (e.g., physical, occupational, respiratory), or medicine might use CBPT so students could practice solving clinical problems from a variety of perspectives, in a manner similar to the approach described in this paper.

\section{Limitations}

As is typical when studying students' learning outcomes, it is difficult to control for all potential intervening variables. Specifically, the pedagogical methods used in this study were applied simultaneously with students' other coursework. Thus, it is possible that factors beyond CBPT (i.e., pedagogies employed in other coursework) might have impacted the findings noted here. Further, there were other facets of students' semester-long learning outside of this course and regarding this experience. For example, students' weekly reading and reflections could have contributed to our findings. Given that this study was an ecologically valid investigation conducted during a university semester, it is impossible to determine whether our findings are a result of CBPT alone.

Additionally, although qualitative data was coded with high levels of reliability and quantitative data was obtained using a validated instrument (MAI), some level of subjectivity could have been present in both data collection and analysis. Students self-reported reflection and MAI data, which may have impacted the objectivity of information shared. Similarly, data were coded systematically; 
however, some level of subjective interpretation of codes and reflection statements may have influenced qualitative data analysis.

\section{Conclusion}

Students appear to have made demonstrable changes in metacognition and higher-level cognitive processing potentially due to this IS experience. Thus, CBPT may hold promise in fostering significant learning and changes in metacognitive awareness in contexts in and beyond CSD in a relatively short period of time. Thus, CBPT may be ideal for some course instructors given the brief nature of a typical academic term.

Any new pedagogy should be studied in a variety of ways. Regarding CBPT, future research efforts might focus on expanding this work to other disciplines to determine whether similar positive outcomes are observed. Also, while difficult to implement in an academic context, a quasiexperimental research design might help eliminate ambiguity as to the specific variables that contributed to the described findings. Regardless, the implementation of CBPT likely tasks students with practicing skills that may enhance metacognition and cognitive processing beyond the use of CBL or perspective-taking alone.

\section{Appendix 1: CBPT Activity for Alaryngeal Communication}

\section{Activity Description}

Students were presented with the following case, one part at a time. Facilitators randomly assigned "roles" for each student such as: patient, spouse, surgeon, employer, best friend, daughter, or speechlanguage pathologist. Students wore nametags identifying their role for others in the discussion group. The IS facilitator led a discussion where each student was encouraged to respond professionally and/or emotionally to the situation described by adopting the perspective/persona of their assigned role.

\section{Part 1: Diagnosis and Treatment Planning}

Anne is a 53-year old, married woman who was diagnosed with squamous-cell cancer of the larynx approximately 10 days ago. She is meeting today with her cancer care team to talk about treatment options. Her surgeon is recommending a total laryngectomy due to the fact that her laryngeal tumor was found to have crossed the anterior commissure of the larynx. Her radiologist has suggested postsurgical radiation to minimize the chance of recurrence. Other than her cancer, Anne is in good health and is active socially. She is a receptionist at a law firm, where she has worked for the last 25 years.

\section{Part 2: Post-Surgical Adjustment}

In the period immediately following her total laryngectomy, as well as through an extended period of radiation therapy, Anne communicated with an electrolarynx (EL). She became a very proficient user of a neck-type device. With the exception of the mechanical quality of the EL signal, it met her communication needs fully and no restrictions were noted. However, at 7 months post-laryngectomy, Anne found that use of the EL was not always easy or efficient. For this reason, Anne is now seeking information on a secondary tracheoesophageal (TE) puncture from her surgeon and speech-language pathologist. 


\section{Part 3: Post-Secondary TE Procedure}

In consulting with her surgeon and speech-language pathologist, a recommendation for Anne to undergo a secondary TE procedure is made. Anne's remaining concerns center on the expense of the TE procedure and general issues related to its management and care. She has requested a meeting of the whole cancer care team to review options, responsibilities, and make a final determination.

Based on Doyle, P. (2017). Communication Challenges in Laryngeal. In Author \& Author (Eds.) Laryngeal Cancer: An Interdisciplinary Resource for Practitioners (p. 82) Thorofare, NJ: Slack.

\section{References}

Adams, N. E. (2015). Bloom's taxonomy of cognitive learning objectives. Journal of the Medical Library Association, 103(3), 152-153. http://dx.doi.org/10.3163/1536-5050.103.3.010

Bandura, A. (1977). Self-efficacy: Toward A unifying theory of behavioral change. Psychological Review 84(2): 191-215.

Barkley, E. (2010). Student engagement techniques: A bandbook for college faculty. San Francisco, CA: JosseyBass.

Bartimote-Aufflick, K., Bridgeman, A., Walker, R., Sharma, M., Smith, L. (2016). The study, evaluation, and improvement of university student self-efficacy. Studies in Higher Education, 125. http://dx.doi.org/10.1080/03075079.2014.999319

Biggs, J. B. (2003). Teaching for quality learning at university: what the student does (2nd ed.). Buckingham: Society for Research into Higher Education, Open University Press.

Biggs, J.B. (1987). Student approaches to learning and studying. Hawthorn, Victoria: Australian Council for Education Research.

Blatt, B., LeLacheur, S., F., Galinsky, A. D., Simmens, S. J., \& Greenberg, L. (2010). Does perspective-taking increase patient satisfaction in medical encounters? Academic Medicine, 85(9), 1445-1452. http://dx.doi.org/10.1097/ACM.0b013e3181eae5ec

Bloom, B., Englehart, M. Furst, E., Hill, W., \& Krathwohl, D. (1956). Taxonomy of educational objectives: The classification of educational goals. Handbook. I: Cognitive domain. New York, Toronto: Longmans, Green.

Bonwell, C., \& Eison, J. (1991). Active learning: Creating excitement in the classroom (ASHE-ERIC Higher Education Report No. 1). Washington, DC: George Washington University.

Chin, C. and Brown, D.E. (2000). Learning in science: a comparison of deep and surface approaches. Journal of Research in Science Teaching, 37, 109-138. http://dx.doi.org/10.1002/(SICI)1098-2736(200002)37:2<109::AID-TEA3>3.0.CO;2-7 
Datta, A., \& Ray, J. (2016). Case based learning in undergraduate pathology - A study to assess its efficacy and acceptability as teaching-learning tool. International Archives of Integrated Medicine, 3(6), 93-100. http://iaimjournal.com/wpcontent/uploads/2016/06/iaim 2016 0306 16.pdf

de Bono, Edward (1985). Six thinking hats: An essential approach to business management. Little, Brown, \& Company

Dunlosky, J. \& Metcalfe, J (2009). Metacognition. Los Angeles, CA: Sage Publishing.

Fink, L. D. (2013). Creating significant learning experiences: An integrated approach to designing college courses. San Francisco, California: Jossey-Bass.

Flavell, J. H. (1979). Metacognition and cognitive monitoring: A new area of cognitivedevelopmental inquiry. American Psychologist, 34(10), 906-911.

Foran, J. (2002). The case method and the interactive classroom. NEA Higher Education Journal, 17(1): 41-50. http://www.nea.org/assets/img/PubThoughtAndAction/TAA 01Sum 05.pdf

Friberg, J. C. \& Vinney, L.A. (Eds.). (2017). Laryngeal cancer: An interdisciplinary resource guide for practitioners. Thorofare, NJ: Slack Publishing, Inc.

Friberg, J. C., Vinney, L. A., Heineman, A., \& Estand, M.(under review). Case-based perspective taking: A new active learning pedagogy. Gauisus.

Galinsky, A. D., \& Ku, G. (2004). The effects of perspective-taking on prejudice: The moderating role of self-evaluation. Personality and Social Psychology Bulletin, 30(5), 594-604. https://doi.org/10.1177/0146167203262802

Ginsberg, S., Friberg, J.C., \& Visconti, C. (2012). Scholarship of teaching and learning in speech-language pathology and audiology: Evidence-based education. San Diego: Plural.

Koriat, A. (2008). Easy comes, easy goes? the link between learning and remembering and its exploitation in metacognition. Memory \& Cognition, 36(2), 416-428. https://doi.org/10.3758/MC.36.2.416

Koriat, A., Ackerman, R., Lockl, K., \& Schneider, W. (2009). The memorizing effort heuristic in judgments of learning: A developmental perspective. Journal of Experimental Child Psychology, 102(3), 265-279. http://doi.org/10.1016/i.jecp.2008.10.005

Koriat, A., \& Bjork, R. A. (2006). Mending metacognitive illusions: A comparison of mnemonicbased and theory-based procedures. Journal of Experimental Psychology: Learning, Memory, and Cognition, 32(5), 1133-1145. http://dx.doi.org/10.1037/0278-7393.32.5.1133

Magno, C. (2010). The role of metacognitive skills in developing critical thinking. Metacognition and Learning, 5(2), 137-156. http://dx.doi.org/10.1007/s11409-010-9054-4 
Maslovaty, N., Cohen, A., \& Furman, S. (2008). The structural validity of the perceived traits of the "ideal student" multi-faceted theory about education students. Studies in Educational Evaluation, 34(3), 165-172. https://doi.org/10.1016/j.stueduc.2008.07.003

Nelson, T. O., \& Dunlosky, J. (1991). When people's judgments of learning (JOLs) are extremely accurate at predicting subsequent recall: The 'delayed-JOL effect.' Psychological Science, 2(4), 267-270. https://doi.org/10.1111/j.1467-9280.1991.tb00147.x

Nkhoma, M., Sriratanaviriyakul, N., \& Le Quang, H. (2017) Using case method to enrich students' learning outcomes. Active Learning in Higher Education, 18(1), 37-50. https://doi.org/10.1177/1469787417693501

Prins, F. J., Veenman, M. V. J., \& Elshout, J. J. (2006). The impact of intellectual ability and metacognition on learning: New support for the threshold of problematicity theory. Learning and Instruction, 16(4), 374-387. http://doi.org/10.1016/j.learninstruc.2006.07.008

Richmond, A.S., \& Hagan, L.K. (2011). Promoting higher level thinking in psychology: Is active learning the answer? Teaching of Psychology, 38(2), 102-105. https://doi.org/10.1177/0098628311401581

Rum, S. N., \& Ismail, M. (2014). Metacognitive awareness assessment and introductory computer programming course achievement at university. International Arab Journal of Information Technology, 13.

Schraw, G. (1998). Promoting general metacognitive awareness. Instructional Science, 26(1-2), 113-125. https://doi.org/10.1023/A:1003044231033

Schraw, G. \& Dennison, R.S. (1994). Assessing metacognitive awareness. Contemporary Educational Psychology, 19, 460-475. https://doi.org/10.1006/ceps.1994.1033

Trommelen, R.D., Karpinski, A., Chauvin, S. (2017) Impact of case-based learning and reflection on clinical reasoning and reflection abilities in physical therapist students. Journal of Physical Therapy Education, 31(1), 21-30.

Vescio, T. K., Sechrist, G. B., \& Paolucci, M. P. (2003). Perspective taking and prejudice reduction: The mediational role of empathy arousal and situational attributions. European Journal of Social Psychology, 33(4), 455-472. http://dx.doi.org/10.1002/ejsp.163

Vohs, K.D. \& Baumeister, R.F. (2004) Understanding self-regulation. In K. D. Vohs (Ed.), Handbook of self-regulation: Research, theory, and applications. (pp. 1-9). New York, NY US: Guilford Press.Vos, H. \& De Graaff, E. (2004). Developing metacognition: a basis for active learning. European Journal of Engineering Education, 29(4). 543-548. http://dx.doi.org/10.1080/03043790410001716257

Young, A., \& Fry, J. (2008). Metacognitive awareness and academic achievement in college students. Journal of the Scholarship of Teaching and Learning, 8(2),1-10. https://josotl.indiana.edu/article/view/1696 